\title{
Correction to: Concomitant aortic valve replacement, mitral valve replacement, and coronary artery bypass grafting for aortic stenosis and mitral regurgitation in a patient with relapsing polychondritis
}

Eiri Kisamori ${ }^{1} \cdot$ Satoru Otani $^{1} \cdot$ Tsuyoshi Yamamoto $^{1} \cdot$ Michiru Nishiki $^{1} \cdot$ Yuki Yamada $^{1} \cdot$ Taichiro Matsumoto $^{1}$

Published online: 28 June 2019

(c) The Japanese Association for Thoracic Surgery 2019

\section{Correction to: \\ General Thoracic and Cardiovascular Surgery \\ https://doi.org/10.1007/s11748-019-01130-6}

In the original publication of the article, the figures were published in wrong order. The Figs. 1, 2, 3 should appear as in this correction.

The original article has been corrected.

The original article can be found online at https://doi.org/10.1007/ s11748-019-01130-6.

Eiri Kisamori

e.kisamori@gmail.com

1 Department of Cardiovascular Surgery, National Hospital Organization Iwakuni Clinical Center, 1-1-1 Atagocho, Iwakuni, Yamaguchi 740-8510, Japan 
Fig. 1 a, b The right coronary angiogram showed no stenosis including ostium. c, $\mathbf{d}$ The left coronary angiogram showed no stenosis
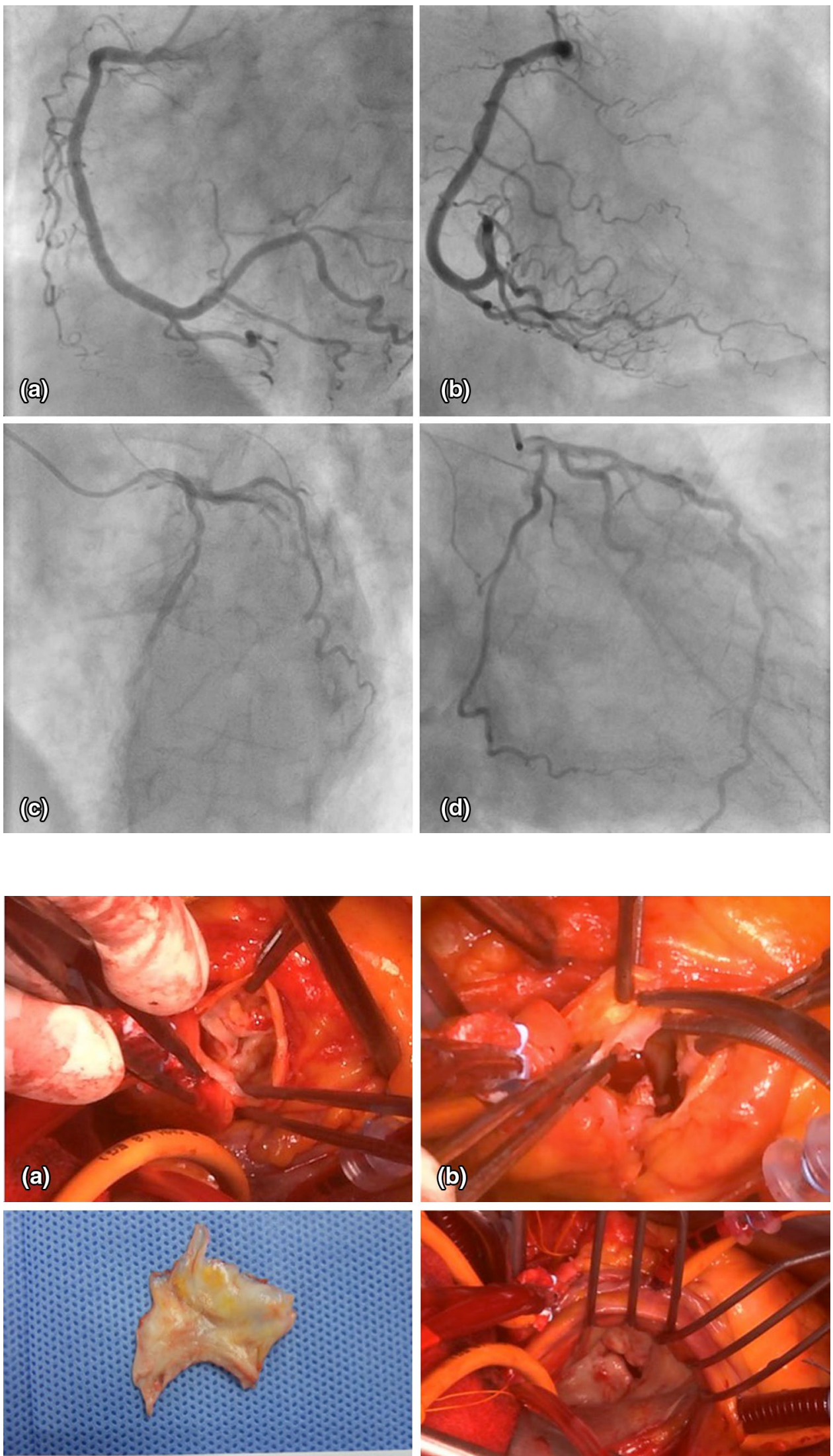

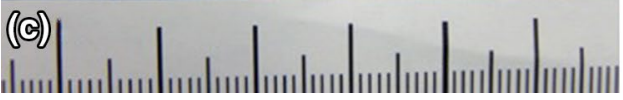

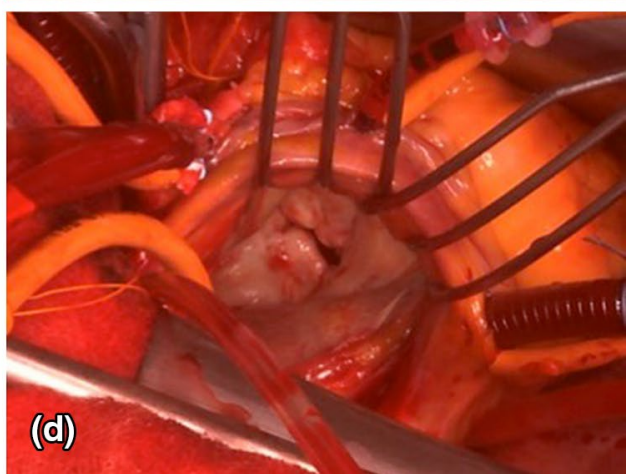

Fig. 2 a The gross appearance of the aortic valve. The aortic valve was tricuspid and the leaflets were thickened and fused. b The connective tissue surrounding the inner layer of the sinus of Valsalva was resected as a layer. $\mathbf{c}$ Excision of the connective tissue surrounding the sinus of Valsalva. $\mathbf{d}$ The gross appearance of the mitral valve. The mitral leaflets were also thickened, and the posterior leaflet was shortened 


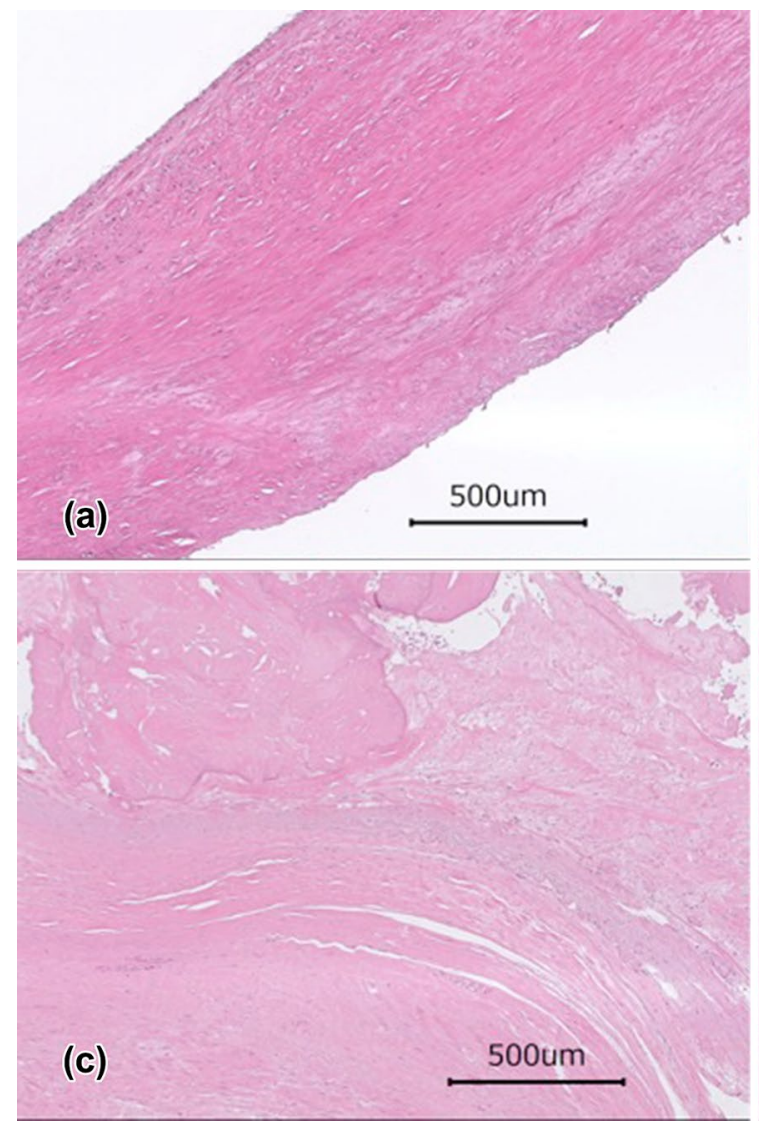

Fig. 3 a, b Pathological findings of the white connective tissue surrounding inner layer of the sinus of valsalva showed fibrous degeneration and myxoid degeneration accompanied with lymphocyte and
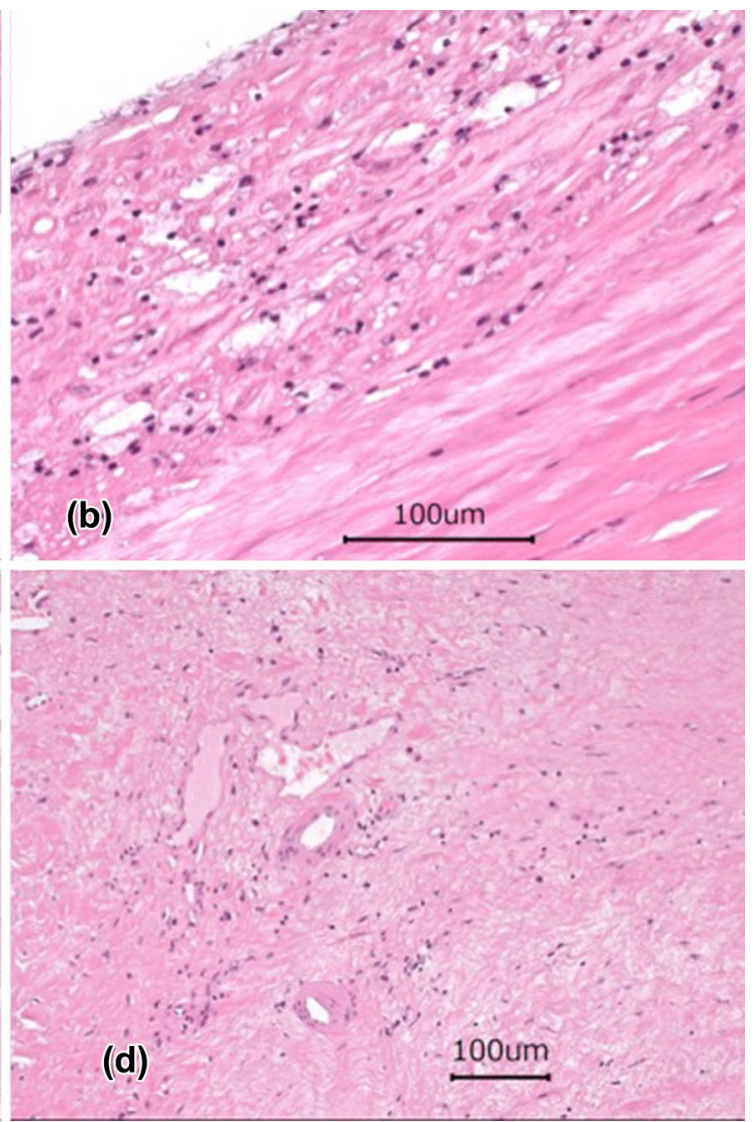

macrophage infiltration (hematoxylin and eosin stain. $\times 40, \times 200$ ). The aortic (c) and mitral valves (d) showed calcification and fibrous degeneration (hematoxylin and eosin stain. $\times 40, \times 100$ ) 